\title{
EL RETRATO DE OSTENTACIÓN DE LAS ÉLITES CHILENAS DEL SIGLO XVIII: GUSTO ARTÍSTICO, ESTILO E ICONOGRAFÍA DE UNA SOCIEDAD EN TRANSFORMACIÓN
}

\author{
COURT PORTRAIT OF 18TH CENTURY CHILEAN ELITE: \\ ARTISTIC TASTE, STYLE, AND ICONOGRAPHY OF A \\ CHANGING SOCIETY
}

\section{NOEMI CINELLI*, LUISA CONSUELO SOLER LIZARAZO**, INMACULADA SIMÓN RUIZ****}

\section{RESUMEN}

A partir del siglo XVIII Chile experimentó un cambio de gustos y de tendencias artísticas, bien testimoniado por el desarrollo del retrato de ostentación como género autónomo respecto del retrato de temática religiosa. Se difundió en particular entre aquellas élites de intelectuales, eclesiásticos y políticos que querían manifestar su individualidad frente a la Monarquía Española, y que vieron en el retrato el vehículo a través del cual proclamar su emancipación.

Palabras clave: Élites chilenas, retratos de ostentación, cambio de gusto, Carlos III de Borbón.

\section{ABSTRACT}

Starting in the 18th century, Chile experienced a change in taste and artistic trends, well attested by the development of court portrait as genre independent from religious portrait. It spread particularly among those elites of intellectuals, clerics, and politicians

* Investigadora Responsable del Proyecto Post Doctorado FONDECYT N ${ }^{\circ} 3140109$. Instituto de Estudios Sociales y Humanísticos, Facultad de Ciencias Sociales y Humanidades, Universidad Autónoma de Chile. Santiago, Chile. Correo electrónico: noemicinelli@gmail.com

** Investigadora Responsable del Proyecto Iniciación FONDECYT Nº 11130190. Instituto de Estudios Sociales y Humanísticos, Facultad de Ciencias Sociales y Humanidades, Universidad Autónoma de Chile. Talca, Chile. Correo electrónico: 1solerl@uautonoma.cl

${ }_{* * \star}$ Investigadora Responsable del Proyecto Regular FONDECYT No 1140292 . Instituto de Estudios Sociales y Humanísticos, Facultad de Ciencias Sociales y Humanidades, Universidad Autónoma de Chile, Talca, Chile. Correo electrónico: isruiz72@gmail.com 
who wanted to express their individuality in relation to the Spanish Monarchy, and who found in portrait painting a vehicle to proclaim their emancipation.

Keywords: Chilean elites, portrait of court, change of taste, Charles III of Bourbon.

Recibido: 12.03.15. Aceptado: 02.06.15.

\section{INTRODUCCIÓN}

E

N EL VARIADO panorama del arte colonial chileno el tema que trataremos a seguir, el retrato en la pintura del siglo XVIII, ha sido hasta hoy menos investigado frente, por ejemplo, al interés despertado por los grandes artistas de los siglos XIX y XX, o por la historia de la arquitectura tanto religiosa como militar y civil (Villegas, 2009; Ivelic, 2011).

Creemos que una de las razones de tal desinterés radique en el afán de los investigadores empeñados en temas chilenos de indagar acerca de las urgentes cuestiones no solo culturales, sino más bien políticas y sociales, procedentes de la proclamación de la República, con el objetivo común de dar forma a una historia del país y por ende una identidad nacional.

A esto debemos añadir la constatación de la indiscutible dificultad de hallar escritos sobre la época, por un lado, a causa de las pérdidas y las dispersiones que registran las instituciones entre sus fondos $y$, por el otro, por las continuas incursiones de los coleccionistas privados en el mundo de las fuentes documentales (Villegas, 2009).

Otra explicación hay que buscarla en la objetiva predilección por la temática religiosa que se registra en la sociedad chilena hasta bien entrado el siglo XVIII, hecho que hace que los ejemplos de retratos de ostentación sean muy escasos, abundando, por el contrario, los retratos de frailes en los grandes ciclos de vidas de santos. Basta con referirnos por ejemplo a "La vida de San Francisco"' (Cruz, 1986), "La vida de San Pedro de Alcántara"2 (Cruz, 1986) y la "Vida de Diego de San Diego de Alcalá”3 (Santander, 2011).

\footnotetext{
${ }^{1}$ El ciclo remonta al año 1684, hoy se encuentra en Santiago de Chile, en el Museo de Arte Colonial de San Francisco.

${ }^{2}$ Se trata de un ciclo realizado en los siglos XVII-XVIII, hoy en el Museo de Arte Colonial de Santiago de Chile.

${ }^{3}$ La obra fue realizada en los años 1705-1715, hoy se encuentra entre el Museo Colonial de Santiago y la Pinacoteca de la Universidad de Concepción.
} 
El siglo XVIII marca en España (como en Europa) la feliz aplicación de los ideales de la Ilustración (Mestre, 1998; Sánchez Blanco, 2002). El proceso se tradujo en numerosas iniciativas que el Rey Carlos III de Borbón puso en marcha desde su subida al trono, con el objetivo de un renovado florecimiento de su reino, también en el ámbito de las bellas artes (Palacio Atard, 2006; Fernández, 2001). Basta con citar la fundación de la madrileña Real Academia de Bellas Artes de San Fernando en 1752 (Bedát, 1989) y la llamada a corte del italiano Giovan Battista Tiepolo y del bohemio Anton Raphael Mengs que se desafiaban entre Glorias y Triunfos en los techos del Palacio Real (Roettgen, 2003; Sánchez Cantón, 1953).

Las reformas emprendidas por Carlos III y realizadas por una multitud de ministros y funcionarios (Kuethe, 1998) conllevaron, tanto en España como en los lejanos territorios americanos de la corona (Guirao de Vierna, 1993; Zuleta, 1989), notables reajustes en la vida económica, social y política, los cuales ineludiblemente influyeron en las actividades culturales y en las artes en particular (Morán, 2003; Paniagua, 2005).

En Chile el absorbimiento de los cánones estéticos propugnados por los nuevos vientos de progreso que soplaban siempre con más fuerza en España fue un proceso lento pero inexorable, que dio sus frutos en un lapso de tiempo más extenso que en el resto de las colonias (Campos, 1989).

Los tiempos y las modalidades con las que Chile llevó a cabo tal proceso dependieron de diferentes factores, y en esta sede creemos oportuno destacar los tres más determinantes: el primero de ellos radica en dos circunstancias, la objetiva lejanía geográfica de Chile respecto a las demás colonias $^{4}$-hecho que ralentizó la implementación de modas y costumbres europeas- y la naturaleza sísmica del territorio andino, que tan solo en el siglo XVIII vio su suelo hecho añicos en dos ocasiones 5 .

El segundo atañe a consideraciones más bien de orden práctico, esto es, la perduración de la tradición del barroco bávaro impulsada por la presencia masiva en todo el territorio chileno -islas incluidas- de los hermanos jesuitas (Araneda, 1967). Ellos mantuvieron bajo su control todo lo relacio-

\footnotetext{
${ }^{4}$ Los gustos, las tendencias y las modas europeas tardaban meses en llegar a Chile a causa de las largas navegaciones desde los puertos españoles hasta América (Cfr. Cruz, 1996).

${ }^{5}$ Recordemos dos terremotos que afectaron catastróficamente Chile en tan solo 20 años: el primero de ellos fue registrado el día 8 de julio de 1730 y se conoce como el "terremoto de Valparaíso"; a este siguió el del 23 de mayo de 1751, pasado a la historia como "el gran sismo de Concepción" (Cfr: Valenzuela, 2012).
} 
nado con la educación y las bellas artes, hasta su expulsión en el año $1767^{6}$ (Valdés, 1985; Moreno, 2007).

Desde su llegada en 1593, además de la misión evangelizadora, los esfuerzos de los jesuitas se focalizaron en dotar el país de escuelas de primeras letras, archivos y bibliotecas implantando el sistema de enseñanza básica, media y superior más eficiente y completo que tuvo Hispanoamérica entre los siglos XVI y XVIII (Matthei, 1968). Con la expulsión de los jesuitas se interrumpió el avance de las formas básicas de institucionalidad cultural en Chile, derivando ello en la ausencia de un organismo central y secular que tutelara las tareas relacionadas con la enseñanza (Villegas, 2009) ${ }^{7}$. Hubo que esperar a don Manuel de Salas para la fundación de la primera Academia Chilena, la llamada San Luis, que a partir de 1797 dictó sus primeras clases de matemáticas y dibujo (Amunátegui, 1895). Los artistas hasta entonces habían basado su formación en el aprendizaje en talleres poco especializados, muchas veces en ámbito familiar (Berríos, 2009).

Un último factor, al que nos parece oportuno dedicar más espacio en este escrito, fue el rol jugado por el Virreinato de Perú, centro de producción cultural muy activo y atractivo para Chile en la época que nos interesa (De Mesa y Gisbert, 1982). A lo largo de tres siglos, desde Lima y Cuzco en particular los conocimientos en cuestiones de bellas artes llegaban y se difundían en toda el área andina, ofreciendo compendios de técnicas artísticas y señalando las directrices a seguir en materia de gusto y temáticas (Cossio del Pomar, 1958; González, 1970; Stastny, 1967).

En particular, las élites chilenas de las que nos ocuparemos más adelante demostraron una prolongada inclinación en el tiempo por la producción de la Escuela Cuzqueña de Pintura (Bravo, 1981). Tal predilección radicó quizás en las tonalidades cálidas e intensas de rojo, tierra de Siena y ocre; o en la reinterpretación del espacio que prescindió de las reglas de la perspectiva aérea, prefiriendo dividir la composición en diferentes escenarios, como si de una historia narrada en un mismo lienzo se tratara. $O$ tal vez se debió al llamativo empleo del brocateado, técnica que, recurriendo al oro aplicado en aureolas y vestimentas, reconducía a los elegantes elementos sevillanos-flamencos e italianizantes embebidos aún de la tradición de la antigua pintura medieval bizantina. Las obras cuzqueñas, que destacan por

\footnotetext{
${ }^{6}$ Recordemos la Pragmática Sanción, orden con la que Carlos III regulaba la expulsión de los jesuitas de los dominios españoles, a la que siguió en 1773 la bula Dominus ac Redemptor, con la que Clemente XIV Ganganelli suprimía la Compañía de Jesús.

${ }^{7}$ Por contra, este hecho hizo que las ideas de Carlos III acerca de la educación encontraran terreno fértil para el desarrollo de formas de enseñanzas seculares.
} 
su brillantez, emanaban solemnidad. Su carácter mestizo es prueba de una tensa y sobrecogedora simbiosis hispano-indígena, cuya expresión máxima se alcanzó en cuadros de temas religiosos, marianos, angélicos, hagiográficos, los que Francisco Stastny $(1967 ; 1994)$ define como cuadros históricos simbólicos, perfecta expresión del sincretismo entre modelos europeos y elementos andinos.

Será, sin embargo, la Escuela Limeña la que en el siglo XVIII focalizará sobre sí la atención de las élites chilenas cuando, urgiendo la necesidad de afirmar su individualidad respecto al mundo español, comienza a autoproclamarse, comisionando los retratos de ostentación de los que nos ocuparemos en el siguiente apartado, y que tienen en el pintor Gil de Castro el mejor intérprete.

Los gustos y tendencias imperantes en el Mediterráneo llegaban a Lima junto con la mercancía de los barcos españoles que navegaban entre Panamá y Cabo de Hornos, facilitados por la presencia en los puertos peruanos de buques franceses tolerados por las autoridades locales (Cruz, 1984). En Francia como en Italia, de Rigaud a Liotard, de Mengs a Batoni, los grandes maestros retratistas cortesanos se libraron de los mesurados modelos promovidos por los Austrias. Dejaban paso a las atmósferas empolvadas y frívolas, a la novedad de la elegancia mundana en las telas en las que el juego de las apariencias hacía resaltar joyas, atuendos y escotes y miradas hasta ahora poco usuales (Calvo, 1990; López, 2001).

Lima experimentó una verdadera metamorfosis, animándose con artistas que, al servicio de los nuevos intendentes, gobernadores y obispos, plasmaron en retratos la imagen de la nueva sociedad inclinada al afrancesamiento típicamente borbónico (Pastor de la Torre, 1999; Wuffarden, 2008). Prueba del cambio es el retrato que representa el "X Obispo de Santiago, Don Manuel Alday y Aspée" (Fig. 1), una de las pocas obras que ha llegado hasta nosotros de la mano del limeño José de Legarda (Silva, 1917). Las noticias ciertas sobre datación y autoría proceden de la misma tela en la que el artista dejó su firma y una larga inscripción. En ella podemos leer de los sucesos de la vida del retratado y de sus virtudes. La ambientación y la pose son típicas del retrato virreinal, aunque el pintor consiga dar a su obra un aire y una originalidad inusuales. El retratado está de pie junto a un mesón donde se apoya con un gesto natural, lo que lleva el ojo del espectador a fijarse en la elegante mitra finamente bordada en el costado derecho de la escena. Son pocos los demás elementos decorativos que dinamizan la tela: el libro Decretales, unos apuntes, el escudo. El autor ha querido fijar con el pincel la caracterización psicológica y espiritual del personaje. Este es el aspecto más destacado de la obra. 


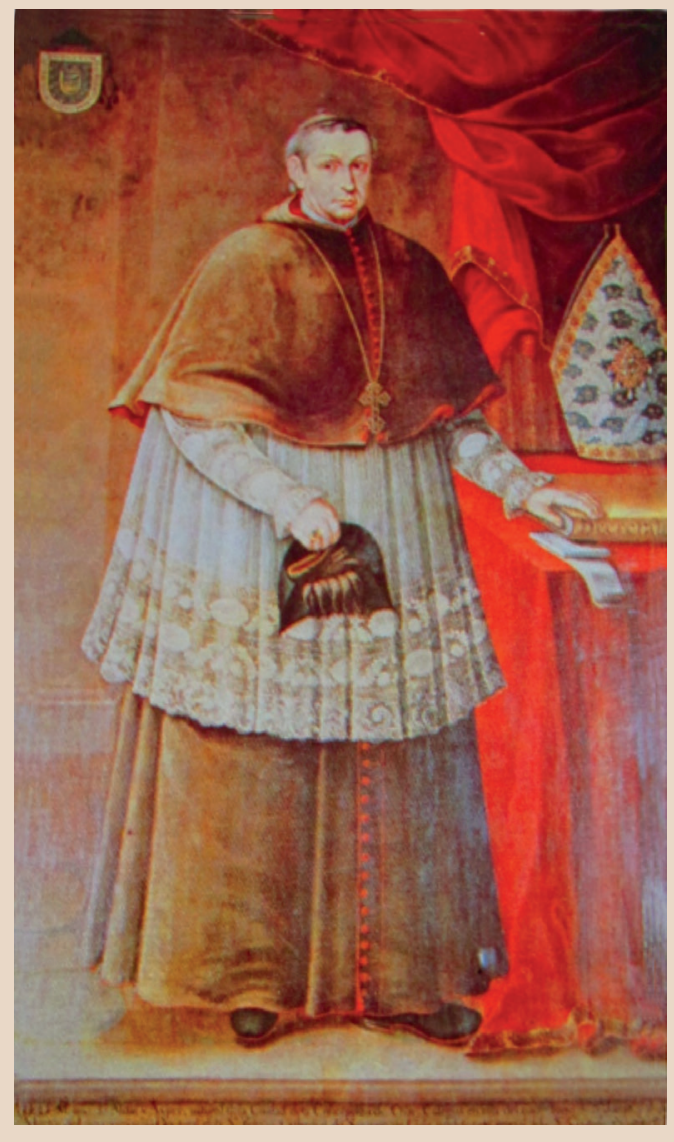

Figura 1. "Retrato del Obispo Don Manuel Alday y Aspée".

Óleo sobre tela, $208 \mathrm{~cm} \mathrm{x} 129 \mathrm{~cm}$, 1772. Museo Histórico Nacional de Santiago.

El siglo XVII había acogido a la pintura, la escultura y la arquitectura entre las artes liberales. El siglo XVIII las convirtió en bellas artes. Este hecho marginó la función cognitiva y comunicativa de la representación artística, exaltando, en cambio, sus aspectos psicológicos. El arte ya no iba dirigido a la razón sino a los sentimientos (Vitta, 2003, p. 211).

El cortinaje no parece sufrir por su propio peso, cae en elegantes líneas que denotan cómo Legarda se distinguió en el manejo del dibujo. El detalle del borde tejido es prueba de la voluntad del pintor de conferir a su pintura una nueva elegancia cortesana, aunque estemos delante de un hombre de Iglesia.

El hábito coral, ligeramente desmesurado en proporción a la cabeza del obispo sobresale en el tratamiento del encaje del roquete en las mangas estrechas y en la parte inferior de la prenda de lino. El verdadero protagonista de la pintura es el color. Las tonalidades de rojo y marrón en diferentes 
matices, que Legarda utiliza para dar solemnidad a Alday prueban el legado de la Escuela Peruana del que fue heredero. Además de resaltar su expresión segura gracias a la mirada y al leve tensarse de los músculos de la cara, como si el pintor le hubiese fijado en un momento de concentración, el rostro respeta el parecido con el retratado. Todo ello contribuye a fijar en la tela la individualidad del obispo.

$\mathrm{Al}$ igual que Lima, Chile tampoco quedó ajeno a tan sensible transformación del gusto, como demuestra la evolución en tres retratos conservados hoy en día en la capital andina. Nos referimos a los de "El corregidor Zañartu y su mujer María Madariaga" (Fig. 2), y del "Maestre de Campo don Santos Izquierdo y Romero y su mujer Doña Tadea Jaraquemada de Águila y Cisterna" (Figs. 3 y 4). El de la primera pareja es uno de los pocos ejemplos de doble retrato que ha llegado hasta nosotros desde la época colonial. Los personajes retratados pertenecieron a la élite intelectual de Santiago. El corregidor Zañartu se distinguió por sus actuaciones en el tema de mejoras urbanísticas en la ciudad de Santiago (Aguirre, 1959). En la obra se

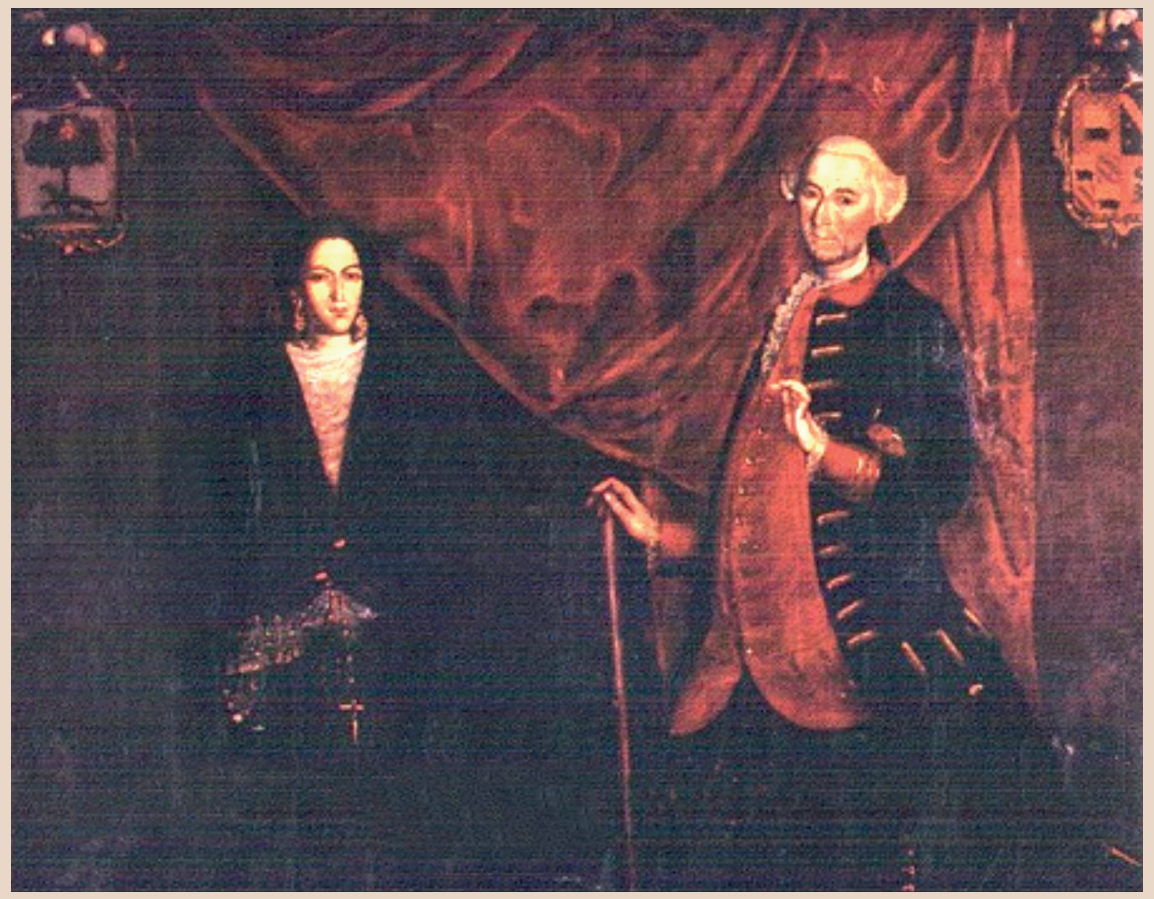

Figura 2. "El corregidor Zañartu y su mujer María Madariaga”. Óleo sobre lienzo, 202 cm x 202 cm, segunda mitad siglo XVIII. Monasterio de Carmen Alto de San Rafael, Santiago. 
detectan claras influencias del retrato austero de los Habsburgo, aunque no faltan detalles que nos hablan de una tendencia hacia las atmósferas rococó. La pareja está de pie, se presenta al espectador en la pose típica del retrato virreinal. Las tonalidades de negro y rojo dan a la escena solemnidad, junto con los trajes que los protagonistas visten, que nos hablan de la inminente entrada a una iglesia. La mujer luce mantilla y saya negras cubriendo una camisa blanca que da luz al rostro ovalado. Destaca la disparidad entre la sobriedad del traje y del peinado recogido en un moño clásico y la exuberancia de las joyas, en particular de los pendientes elegantemente labrados. La expresión del rostro, muy seria, es acentuada por la rigidez de la mirada y la dureza de los labios cerrados.

El corregidor viste un traje sobrio y de rica tela, como el de su mujer: una camisa sin cuello, con una abertura embellecida con una guirindola, con volante de tela muy fina. La chupa negra acampanada luce unos alamares dorados que nos hablan de la posición privilegiada de Zañartu dentro de la élite chilena de aquella época. Rematan el atuendo unas elegantes medias de seta, que evidencian las pantorrillas bien formadas y que contribuían a dar la idea del buen parecer masculino; el bastón muy fino y la peluca empolvada a la manera francesa, con bucles delicados que enmarcan el rostro, nos hablan del cambio de gusto y tendencias en el género del retrato chileno del siglo XVIII.

En el caso de la segunda pareja, estamos delante de dos retratos aparejados, atribuidos a Gil de Castro hasta que los nuevos estudios sobre el pintor peruano han hecho descartar esta hipótesis. Hoy se reconoce en ellos la mano del pintor suizo Martin Petris. Presentan muchas zonas repintadas, especialmente en los dos rostros y en algunos atributos, como el pequeño sombrero que el Maestre de Campo sujeta en la mano derecha (Campos, 1976). Su cuerpo destaca en un fondo muy oscuro, dinamizado por el juego de los azulejos del suelo que, aunque concurran a crear un efecto de perspectiva un tanto distorsionado, dan profundidad a la escena de interior. El traje que luce, también de tonalidades oscuras, está decorado con encajes de oro y con los atributos de las órdenes al que el caballero perteneció. Destaca la mano debajo del pecho, emulando una pose clásica empezada por los romanos, y que una vez más nos habla de las influencias francesas que llegaban al territorio andino según las modalidades ya mencionadas en el presente trabajo. El gesto, en efecto, se había impuesto como norma social de decoro en Francia a finales del siglo XVIII. El realismo de esta figura contrasta con la búsqueda de decorativismo en la representación de la dama, en la que el autor ha dejado más espacio a la interpretación eu- 

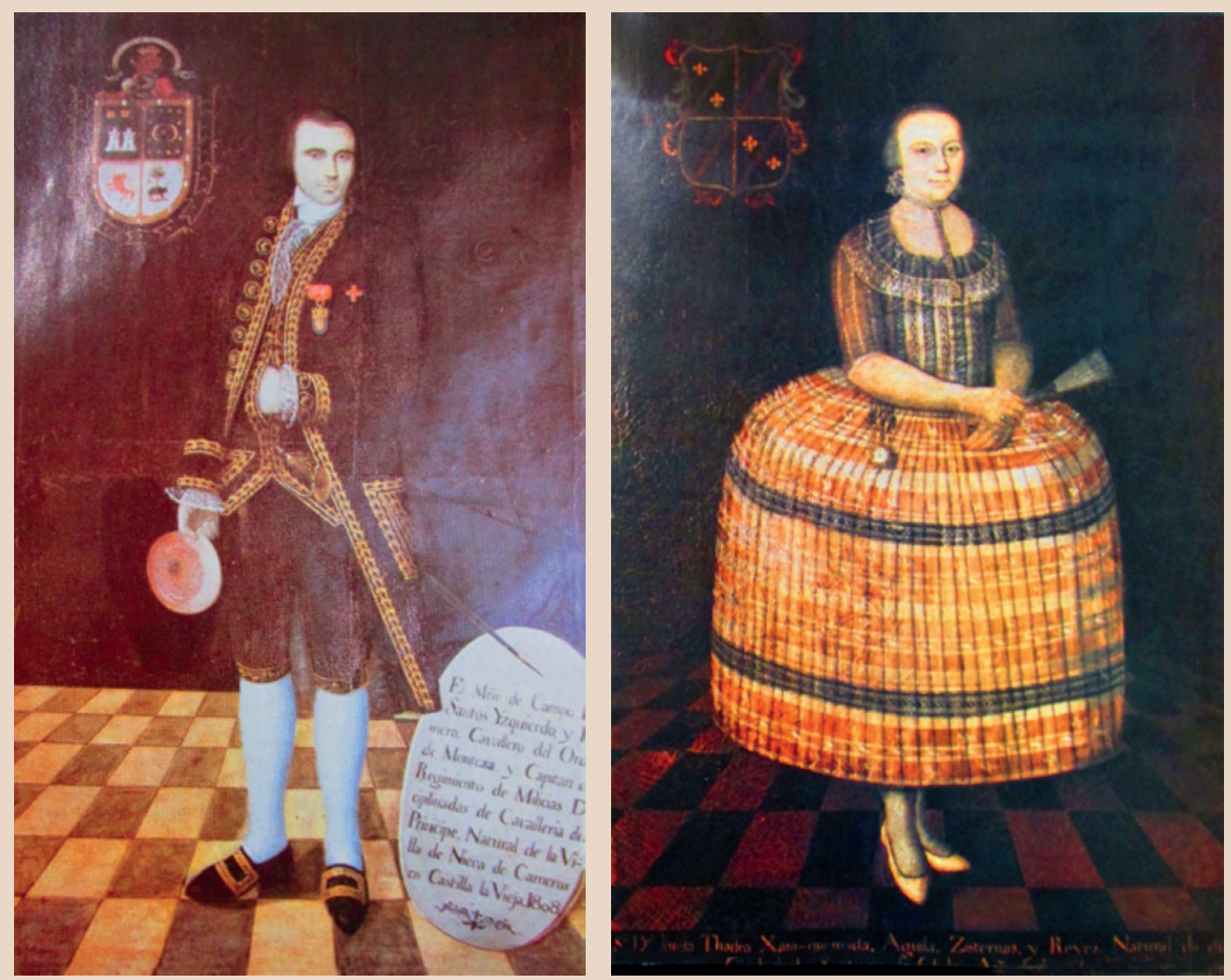

Figuras 3 y 4. "Retrato del Maestre de Campo don Santos Izquierdo y Romero". "Retrato de Doña Tadea Jaraquemada de Águila y Cisterna”. Óleo sobre badana, 208 cm x 124 $\mathrm{cm}$. Aunque en las inscripciones leemos " 1808 ", tenemos que fechar la obra a finales de siglo XVIII, alrededor de 1798, como prueban los trajes de los protagonistas. Colección particular Izquierdo Sanfuentes, Santiago.

ropea del género del retrato. Igual ambientación de la obra que le hace de pendant, aquí destaca el traje de Tadea, amplio, acampanado y finamente definido. La particularidad en este cuadro, creemos, reside en los atributos que la dama presenta: la preciosa parure de perlas blancas que ciñe su cuello y termina en un juego de tres hilos anudados en el pecho; el abanico en la mano derecha, y el delicado reloj de faltriquera con lujosa leontina. Estos detalles ya adornaban los retratos femeninos que el pintor sajón An- 
ton Raphael Mengs había dejado en las cortes europeas, desde la de Dresde hasta la de Madrid. Las tonalidades del rostro y del traje nos recuerdan, en efecto, la translúcida inocencia cromática de las estatuas de porcelana que apreciamos en el boceto de la joven María Luisa de Parma de Mengs, hoy en el Museo del Prado.

\section{EL RETRATO DE OSTENTACIÓN EN CHILE EN LAS ÚLTIMAS DÉCADAS DE LA COLONIA}

Además de los ecos recibidos por la dinámica capital peruana en tema de retrato, en Chile se dieron unas felices circunstancias que favorecieron el desarrollo del género de ostentación como expresión independiente respecto al retrato de temática religiosa, dentro de una más general tendencia de las artes hacias formas -definidas por comodidad en estas páginas- neoclásicas.

En primer lugar, el hecho que estas tierras empezaron a poblarse de artistas europeos del calibre del romano Joaquín Toesca y Ricci, portadores de una verdadera renovación en cuestiones de gusto a través de la transformación arquitectónica y urbanística del centro neurálgico chileno, eso es, Santiago (Modiano, 1993). El impulso edilicio, en efecto, fue el principal conducto a través del cual las formas neoclásicas llegaron a Chile 8 .

En segundo lugar, con los navíos españoles y franceses, llegaban a los puertos de Valparaíso y Concepción ${ }^{9}$ los nuevos escritos de arte que en Europa estaban alimentando una verdadera reforma del debate científico entorno a las $\operatorname{artes}^{10}$.

Tercer elemento catalizador de un cambio de gusto a finales de siglo XVIII fue la implantación de la primera Academia de Bellas Artes en Santiago, la ya mencionada de San Luis, fruto de los esfuerzos incansables de

\footnotetext{
${ }^{8}$ De la misma manera que estaba pasando en España, la intensa labor arquitectónica estaba respondiendo a la voluntad de la Corona de incrementar la actividad edilicia en función de la implementación en aquellos territorios lejanos de reformas jurídicas y sobre todo económicas.

${ }^{9}$ El Reglamento y Aranceles Reales para el Comercio Libre de España a Indias firmado en 1778 por Carlos III involucró también los puertos principales de Chile, Valparaíso, Arica, Concepción.

${ }^{10}$ En Europa la lectura se convirtió en el medio más accesible para llegar a una reforma del debate científico, a través del nuevo impulso recibido por la prensa y por la ampliación del público interesado en cuestiones artísticas. Los tratados y las publicaciones periódicas representaron la prueba del hecho que en el Siglo de Las Luces el arte había alcanzado un protagonismo como tema de debate cotidiano hasta ahora desconocido, considerando también que las tradicionales formas de divulgación de materias artísticas hasta el momento iban dirigidas solo a un público elitista.
} 
Manuel de Salas, culto, amante de la literatura como del dibujo y de la historia, y verdadero espíritu ilustrado de una sociedad en transformación (Ripamonti, 2010).

La multiplicación de los retratos en la segunda mitad del siglo, si por un lado prueba el deseo de las élites chilenas de aparentar la condición y el bienestar de pudientes americanos, por el otro es testimonio de una nueva inspiración cortesana de las renovadas corrientes neoclásicas propugnadas por el academicismo europeo (Montes, 2008).

Todos estos elementos hicieron que a partir de la segunda década del 1700 en Chile se produjeron retratos que, aunque no podamos agrupar por su estilo o por los modelos en los que parecen inspirarse, nos permiten especular acerca de la difusión de la práctica de este género en ámbito andino.

Si bien las guerras de independencia significaron la pérdida de la mayoría de las obras guardadas en el Palacio de la Real Audiencia, en el Cabildo y en el Palacio Arzobispal (Pereira, 1965), hoy en día se conservan ejemplos de retratos que bien ilustran la iconografía colonial chilena. Entre ellos, cabe citar el "Retrato de Don Fermín Francisco de Ustáriz" (Fig. 5), probablemente realizado en Lima, como era costumbre a principio de siglo XVIII. Es uno de los más destacados ejemplos de retratos del 1700. En él es evidente el cambio de gusto que paulatinamente la sociedad chilena estaba experimentando, reflejo del cambio de dinastía Habsburgo-Borbones que se había producido en España. El refinado afrancesamiento de la moda queda evidente en el atuendo del militar y comerciante Ustáriz, figura emblemática del 1700 en América. La riqueza decorativa de la escena une los motivos de la pintura mural de la región del Altiplano y los cánones del género del retrato europeo (Amunátegui, 1910). La inscripción en el primer plano del cuadro, la expresión serena en el rostro joven y la elegancia del cuerpo airoso contribuyen a ennoblecer la figura. El cortinaje en la izquierda es tratado como la quinta de un teatro, y los motivos floreales que le adornan enmarcan la escena junto al mesón de la derecha, creando un entorno fastuoso. Ustáriz viste ropa de encaje suntuosa y elegante, con casaca roja con bordados de oro, que deja entrever la camisa blanca. Las medias de seda negra, el sutil espadín y el tricornio, una vez más, son herencia de los retratistas franceses. Completa la escena un detalle muy poco usual en las obras chilenas de esta época como es el de la ventana que se abre sobre un panorama marítimo de la ciudad de Concepción.

El proceso de transición en las bellas artes empezado con los Borbones en España y cuyos ecos llegaron a Chile según las modalidades a la que hemos hecho mención más arriba, tuvo su raisond'etre en el impulso dado 


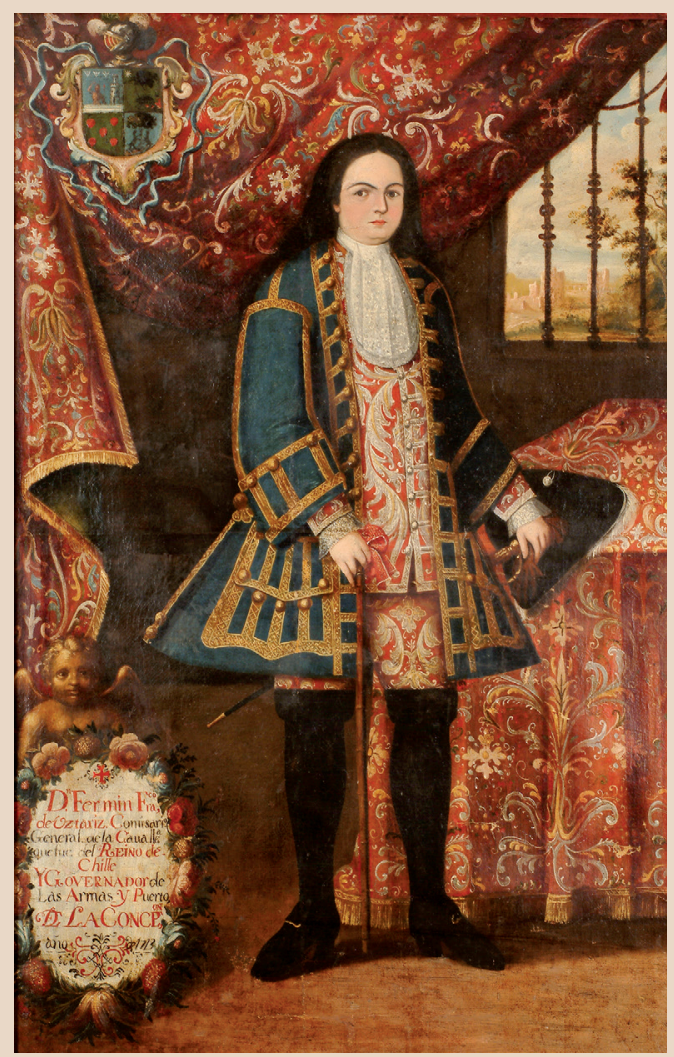

Figura 5. "Retrato de Don Fermín Francisco de Ustáriz”. Óleo sobre tela, $189 \mathrm{~cm}$ x 128 cm, 1723. Colección Particular, Estados Unidos.

a la arquitectura, y llegó a involucrar paulatinamente también la pintura. A finales del siglo XVIII si bien continuaban las comisiones de retratos de temática religiosa, la sociedad criolla, que en pocas décadas se habría convertido en la élite política y cultural de la Emancipación, quiso ser la protagonista de las telas. Es en este momento cuando los retratos de ostentación de la nueva élite chilena, usando las palabras de Alfredo Jocelyn-Holt, "hacen desaparecer los retratos de autoridades metropolitanas, al igual que la noción de ciudadano hace desaparecer la de súbdito" (1999, p. 90). Esto no impide encontrar retratos de autoridades eclesiásticas empreñados todavía de atmósferas típicas del retrato de corte limeño. En este punto cabe citar el "Retrato del Obispo Francisco de Borra José Marán" (Fig. 6). La obra remonta a finales del período colonial y es una de las pocas obras de cierta atribución: correspondería al pintor santiaguino de principios del siglo XIX Joaquín Mesías. En el retrato de Marán (Hanisch, 1990), de medio busto, el autor ha querido resaltar la fundación de la Parroquia de La 
Figura 6. "Retrato del Obispo Francisco de Borra José Marán”. Óleo sobre tela, $114 \mathrm{~cm} \times 87$ $\mathrm{cm}$. Datación: primeros años del siglo XIX. Museo de la Catedral de Santiago.

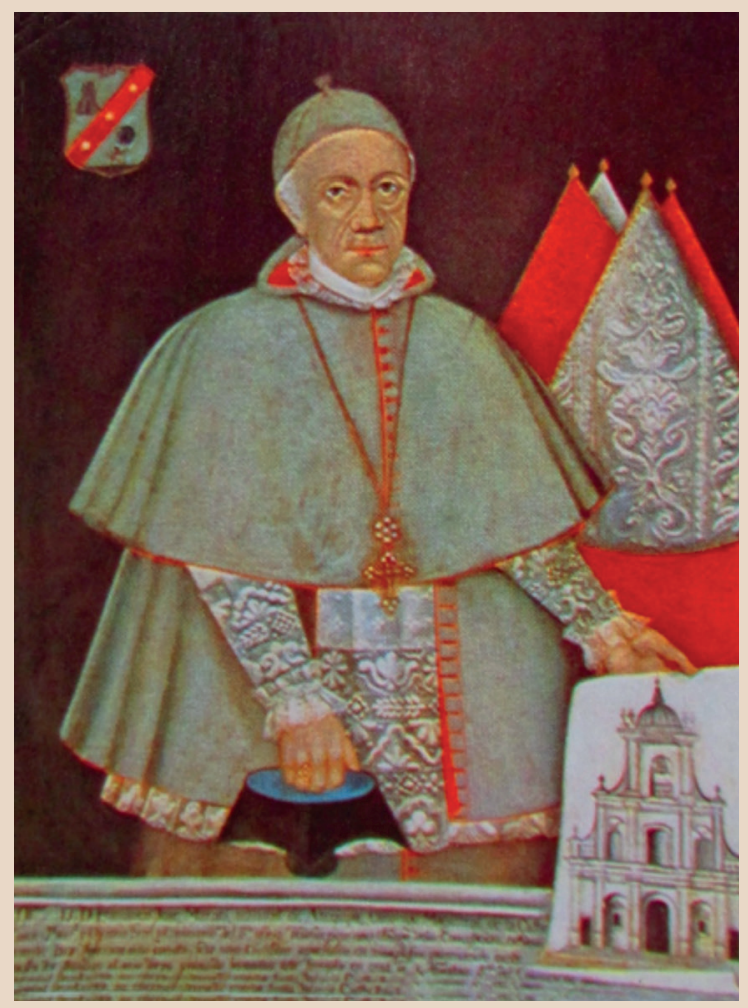

Estampa Volada, representándolo sosteniendo una maqueta de ésta, según costumbre en la iconografía del retrato de tema religioso (Duarte, 2001, p. 22). Hay que subrayar la perfecta realización del dibujo de la fachada de la iglesia, cuyo arquitecto fue el principal discípulo de Joaquín Toesca, Juan José de Goycoolea y Zañartu ${ }^{11}$. Además de ser un valioso documento para la historia de la pintura chilena, el cuadro es una fuente de primaria importancia para la historia de la arquitectura santiaguina neoclásica, ya que la Iglesia representada quedó destruida en el año 1822, siendo entonces lo que apreciamos en el retrato de Marán uno de los pocos testimonios de su aspecto original. $\mathrm{Al}$ igual que en el retrato del Obispo Alday, en la escena hay pocos elementos decorativos, todos alusivos al cargo desempeñado en

${ }^{11}$ La construcción se inició en 1805, quedando terminada en 1814, sin que su fundador pudiera verla, al morir en 1807. El terremoto de 1822 destruyó la Iglesia. 
la ciudad de Santiago. Sin particular atención por la perspectiva, en el fondo del cuadro sobresale una mitra ligeramente desproporcionada respecto de la composición de la escena. El traje sobrio (destaca el roquete decorado en las mangas), la pose casi frontal, el escudo con sus armas y la cartela inferior con la leyenda completan la representación. Falta cierta introspección psicológica en el personaje y el gesto de la mano derecha sujetando la birreta resulta poco natural. Una vez más el protagonista es el color, cuyas tonalidades y pinceladas enérgicas crean diferentes planos en la escena.

La evidente necesidad de la creación de una iconografía postcolonial respondió en Chile a la voluntad de la sociedad de verse mostrada en obras que reflejaban la identidad, y por ende las diferencias, que la distinguían de la aristocracia española. Si bien algunos retratos nos dan prueba de esta toma de conciencia a finales de siglo, habría que esperar al Mulato Gil para que las transformaciones sociales y culturales se tradujeran en gracia estilizada en la tela. Basta con citar el "Retrato de Doña Nicolasa de la Morandé y Prado de Andía y Varela". Hemos elegido una de las obras maestras del peruano Gil de Castro como prueba del cambio (Fig. 7) que la sociedad chilena experimentó en el delicado momento histórico del pasaje desde la época colonial a la proclamación de la República. Podemos, en efecto, considerar al pintor limeño el eslabón entre el retrato virreinal y las nuevas tendencias artísticas europeas que, con la aparición de Napoleón en la escena política, conllevaron la adopción de estilo imperio en la pintura, como en la moda.

En el retrato podemos, en efecto, observar que Gil trata el espacio y la forma de la figura de adueñarse de él, según los mismos principios de la pintura colonial: Nicolasa está retratada de frente, apoyada en un mesón cuyos contornos crean un ambiente plano, gracias al conjunto de líneas que desde el primer plano guía el ojo del espectador hacía el fondo de la escena, hasta el gran cortinaje que hace de quinta (Góngora y Sagredo, 2011). Destacan una vez más el empleo del color intenso que subraya además de la bonita silueta de la mujer, los preciosos elementos decorativos que la acompañan. Todo se juega en el contraste entre el celeste del vestido y el rojo del trasfondo. El empleo de estos colores responde a un criterio de pureza formal anhelado por las corrientes artísticas de principio de siglo XIX en Europa. Y también llaman a la mente el significado político que estos colores tuvieron para Chile.

El pincel de Gil de Castro ha fijado en la tela la singularidad de la retratada, por un lado, su cuerpo, tratado como modelo de arcaica pureza tal y como los dictámenes neoclásicos sugerían; por el otro, la introspección psi- 
Figura 7. "Retrato de Doña Nicolasa de la Morandé y Prado de Andía y Varela". Óleo sobre tela, $104 \mathrm{~cm} \mathrm{x}$ $81 \mathrm{~cm}, 1814$. Pinacoteca de la Universidad de Concepción.

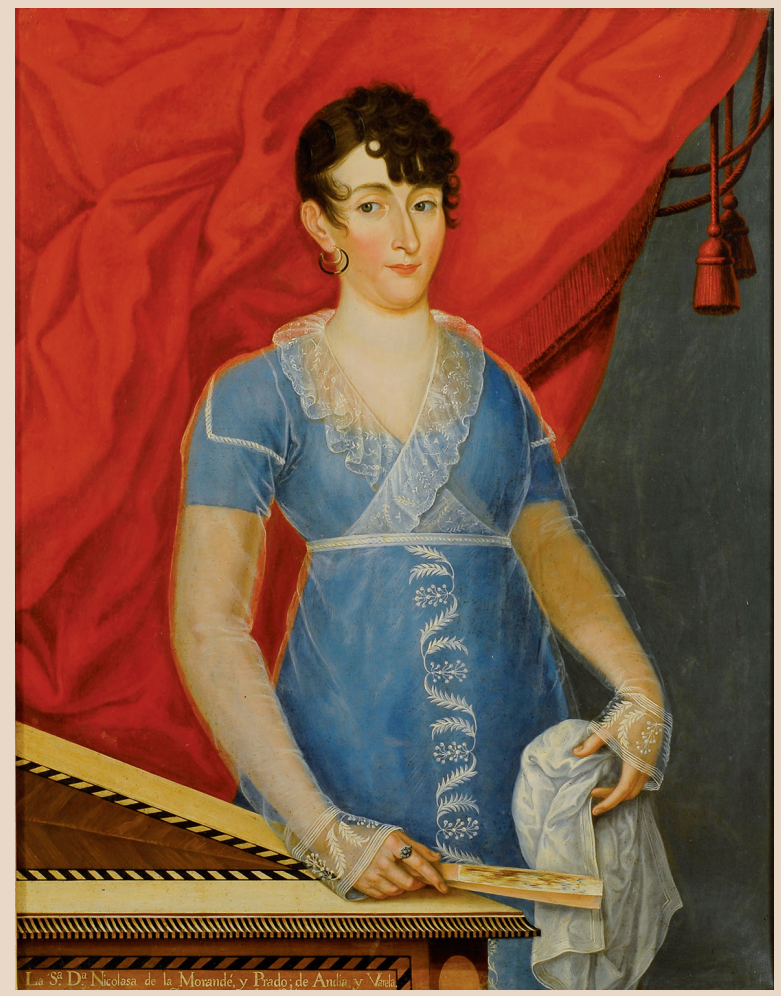

cológica, con su mirada vivaz y serena en un rostro delicado, que la espalda erecta hace resaltar naturalmente. Los años de formación de Gil resultan claros en el tratamiento que reserva al traje de Nicolasa. El manejo del dibujo ya es maduro, destaca en el peinado detallado y en las transparencias del traje a la moda de inspiración grecorromana, que donan a la dama la elegancia típica de la élite americana, nueva alma pulsante de Chile.

El rol jugado por Gil de Castro en el panorama de las bellas artes chilenas fue fundamental: por un lado en función de las innovaciones estilísticas que supo introducir en el género del retrato, y que permiten decir que los dictámenes neoclásicos propugnados por el academicismo europeo llegan gracias a su obra a la perfecta actuación en la pintura. Por el otro, Gil de Castro agilizó en Chile la construcción de un imaginario colectivo de identidad nacional. 


\section{REFERENCIAS}

Aguirre, L. (1959). Españoles chilenos. Historia, cultura, instituciones, actualidad, personalidades. Valparaíso, Chile: sn.

Amunátegui, M. (1895). Don Manuel de Salas. Santiago, Chile: Imprenta Nacional.

Amunátegui, M. (1910). Los precursores de la Independencia de Chile. Santiago, Chile: Imprenta, Litografía i Encuadernación Barcelona.

Araneda, F. (1967). “El barroco jesuita chileno". Atenea, 44(418), 85-122.

Bedát, C. (1989). La Real Academia de Bellas Artes de San Fernando de Madrid (1744- 1808). Madrid, España: Fundación Universitaria Española.

Berríos, P. (2009). "Del taller a las aulas: La institución moderna del arte en Chile (1797-1910)". Boletín de la Academia Chilena de la Historia 98, 371-375.

Bravo, B. (1981). El barroco en Hispanoamérica: manifestaciones y significación. Fondo Histórico y Bibliográfico José Toribio Medina. Santiago, Chile: Biblioteca Nacional de Chile.

Calvo, J. (1990). De los Austrias a los Borbones. Madrid, España: Historia 16.

Campos, F. (1976). Los defensores del Rey. Santiago, Chile: Ed. Andrés Bello.

Campos, F. (Ed.). (1989). Estudios sobre la época de Carlos III en el Reino de Chile. Santiago, Chile: Ediciones de la Universidad de Chile.

Cossio del Pomar, F. (1958). Arte del Perú Colonial: Dibujos de Emilio Sánchez y Robert Davison. México: Fondo de Cultura Económica.

Cruz, I. (1984). Arte: lo mejor en la historia de la pintura y escultura en Chile. Pt 10, Cap. I, 57-112. Santiago, Chile: Ed. Antártica.

Cruz, I. (1986). Museo de San Francisco. Santiago, Chile: Ministerio de Educación Pública. Departamento de Extensión Cultural.

Cruz, I. (1996). El traje: transformaciones de una segunda piel. Santiago, Chile: Eds. Universidad Católica de Chile.

De Mesa, J. y Gisbert, T. (1982). Historia de la pintura cuzqueña, Vols. 1 y 2. Lima, Perú: Fundación A.N. Wiese.

Duarte, P. (2001). "Razón de identidad histórica y posibilidades de expresión en el espacio público de Independencia". Revista de Urbanismo, 4, 1-38.

Fernández, R. (2001). Carlos III. Madrid, España: Arlanza.

Góngora, Á. y Sagredo, R. (2011). Fragmentos para una historia del cuerpo en Chile. Santiago, Chile: Aguilar Chilena de Ediciones.

González, M. (1970). El Perú y el arte. Lima, Perú: Ed. San Julián.

Guirao de Vierna, Á. (1993). "Las Expediciones a América en el Reinado de Carlos III”. De la Ilustración al Romanticismo: IV Encuentro, Carlos III, dos siglos después: Cádiz, 7-9 de abril 1988. Vol. 1, 245-250.

Hanisch, W. (1990). "Memorias sobre Misiones Jesuitas de 1794-1795”. Historia, 25, 103-159.

Ivelic, M. (ed.) (2011). La pintura en Chile: desde la Colonia hasta 1981. Valparaíso, Chile: Ed. Universitarias de Valparaíso. 
Jocelyn-Holt, A. (1999). El peso de la noche: Nuestra frágil fortaleza histórica; José Gil de Castro y la nueva sensibilidad. $3^{a}$ ed. Santiago, Chile: Ed. Planeta.

Kuethe, A. (1998). "Ministros y Consejeros en la Formación de la Política Colonial de Carlos III, 1763-1776”. Tiempos de América: Revista de Historia, Cultura y Territorio, 2, 35-44.

López, T. (2001). "Entre Austrias y Borbones: Actitudes culturales y religiosas". El cambio dinástico y sus repercusiones en la España del siglo XVIII. Coord. M. Bravo, J. Fernández y J. Delgado, 379-400.

Matthei, M. (1968). Los primeros jesuitas germanos en Chile: 1686-1722, Santiago, Chile, s.n.

Mestre, A. (1998). La Ilustración Española. Madrid, España: Arco Libros.

Modiano, I. (1993). Toesca: Arquitecto itinerante de la tradición clásica del siglo XVIII y otros ensayos. Santiago, Chile: Eds. Del Pirata.

Montes, F. (2008). "Reflejos de una ambición novohispana. Los retratos de los I Condes de Pérez Gálvez por el pintor José María Guerrero (1792)”. Anales del Museo de América, 16, 155-171.

Morán, J. M. (2003). "El arte en la Corte de Carlos III". Carlos III y su época: La monarquía ilustrada. Coord. E. Alonso-Muñumer, I. Barcelona, España: Carroggio, 349-376.

Moreno, R. (2007). Misiones en Chile austral: Los jesuitas en Chiloé 1608-1768. Sevilla, España: Escuela de Estudios Hispano-Americanos de Sevilla. Consejo Superior de Investigaciones Científicas.

Palacio Atard, V. (2006). Carlos III: El Rey de los ilustrados. Barcelona: Ariel.

Paniagua, J. (2005). España y América entre el Barroco y la Ilustración (17221804): II Centenario de la Muerte del Cardenal Lorenzana (1804-2004). León: Ed. Universidad de León.

Pastor de la Torre, C. (1999). Perú, fe y arte en el Virreinato. Córdoba, España: Obra Social y Cultural Caja Sur.

Pereira, E. (1965). Historia del arte del Reino de Chile. Santiago, Chile: Ed. Universidad de Chile.

Ripamonti,V. (2010). "Academia de pintura en Chile. Sus momentos previos". Intus-legere: Historia 4-1, 127-156.

Roettgen, S. (2003). Anton Raphael Mengs: 1728-1779. Munich, Alemania: Hirmer.

Sánchez Blanco, F. (2002). El Absolutismo y las Luces en el Reinado de Carlos III. Madrid, España: Marcial Pons.

Sánchez Cantón, F. (1953). J.B. Tiépolo en España, Instituto Diego Velázquez del Consejo Superior de Investigaciones Científicas. Madrid, España: Blass.

Santander, S. (2011). Pintura colonial. Arte y religiosidad popular: Pintura y escultura siglos XVII y XVIII. Concepción, Chile: Pinacoteca de la Universidad de Concepción.

Silva, C. (1917). Don Manuel de Alday y Aspée: Obispo de Santiago de Chile, 1712-1788. Santiago, Chile: Ed. Universitaria. 
Silva, C. (1967). Breve historia del arte en el Perú: La pintura precolombina, colonial y republicana. Lima, Perú: Editorial Universo.

Stastny, F. (1967). Breve historia del arte en el Perú. Lima: Editorial Universo.

Stastny, F. (1994). Síntomas medievales en el "Barroco Americano". Documento de trabajo $N^{o}$ 63. Instituto de Estudios Peruanos, Serie Historia del Arte No 1.

Valdés Bunster, G. (1985). “El poder económico de los jesuitas en Chile (15931767)”. Boletín de la Academia Chilena de la Historia, 98, 371-375.

Valenzuela, J. (2012). "Relaciones jesuitas del terremoto de 1730: Santiago, Valparaíso y Concepción”. Cuadernos de Historia, 37, 195-224.

Villegas, L. (2009). La enseñanza del dibujo artístico en Chile: 1797-1858 [Tesis doctoral no publicada]. España: Universitat Politècnica de València.

Vitta, M. (2003). El sistema de las imágenes estéticas de las representaciones cotidianas. Barcelona: Paidós.

Wuffarden, L. (2008). "Presencia de la Pintura Novohispana en el Virreinato del Perú”. Histórica 32(1), 161-170.

Zuleta, E. (1989). “Carlos III y la Ilustración en América”. Razón Española: Revista Bimestral de Pensamiento, 33, 41-62. 